\title{
As alteraçóes de linguagem e seus sentidos: efeitos de um trabalho fonoaudiológico em rede ${ }^{1}$
}

\author{
Rosana Carla do Nascimento Givigi, Beatriz Campos Mudo, Bruna de Souza Diógenes, Iara \\ Maria Ferreira Santos
}

Universidade Federal de Sergipe - UFS, São Cristóvão, SE, Brasil

\begin{abstract}
Resumo: Este estudo, realizado no campo da Fonoaudiologia, seguiu os pressupostos epistemológicos do Interacionismo Brasileiro, articulado com a Análise do Discurso e as Redes de Significação. Objetivou analisar os efeitos do trabalho de intervenção com crianças, suas famílias e escolas. A intervenção teve como meta a construção da linguagem e a modificação dos sentidos atribuídos a esses sujeitos. O dispositivo metodológico foi o do método clínico-qualitativo e da pesquisa-ação. Os participantes foram cinco crianças com alterações de linguagem, de idade de 0 a 5 anos, suas famílias e escolas. O período de realização da intervenção em pauta foi de dois anos. Os procedimentos foram distintos para as diferentes redes: criança, família, escola. A terapia fonoaudiológica foi semanal e utilizou-se a abordagem interacionista. Com as famílias foram feitas entrevistas e encontros de grupo de pais. Na escola, as visitas foram semanais e na perspectiva da pesquisa-ação colaborativa. Como resultados destacam-se modificações no comportamento das crianças; modificação dos sentidos dados às alterações de linguagem; tentativas comunicativas; interações mais eficazes; trabalho colaborativo nas escolas, dentre outros. A ideia do desenvolvimento humano constituído através de um processo histórico-cultural de significações foi o fio condutor ao longo do estudo. Verificou-se que após o trabalho em redes houve uma gradual modificação de sentidos das alterações de linguagem por parte dos pais, dos agentes educacionais e das crianças atendidas. Discute-se que as concretas condições de vida e as práticas discursivas se interpelam durante todo o tempo, sendo possível pensar as dinâmicas das relações e os processos em desenvolvimento.
\end{abstract}

Palavras-chave: Sinais, Transtornos da Linguagem, Relações Profissional-Família, Educação, Fonoaudiologia.

\section{Language disorders and their meanings: the effects of a speech-language pathology network activity}

\begin{abstract}
This study follows the epistemological assumptions of the Brazilian Interactionism, articulated with the Discourse Analysis and Meaning Network. The main purpose was to analyze the effects of the intervention work with children, their families and schools. The intervention aimed at the construction of language and the modification of the meanings attached to these subjects. The methodological device used clinical-qualitative and action research. Five children with language disorders aged 0 to 5 years, their families and schools participated in this two-year study. The procedures were distinct for the different networks: child, family, school. The speech therapy sessions were performed weekly and were based on the Interactionist approach. Interviews with the families were conducted, as well as meetings with the group of parents. At school, the weekly visits used the collaborative action research perspective. The main results were modifications in the children's behaviour; modification of the meanings given to language disorders; more communicative attempts; more efficient interactions; and collaborative work in schools. The idea of human development based on a historical and cultural process of significations was the guideline of the study. It was possible to verify that, after the network activity, there was a gradual modification of the meanings of language disorders in parents, educational agents and children. Actual life conditions and discursive practices are interwoven throughout time, enabling to reflect on the dynamics of relationships and developing processes.
\end{abstract}

Keywords: Signs, Language Disorders, Professional-Family Relations, Education, Speech, Language and Hearing Sciences.

Autor para correspondência: Rosana Carla do Nascimento Givigi, Universidade Federal de Sergipe, Cidade Universitária Prof. José Aloísio de Campos, Av. Marechal Rondon, s/n, CEP, São Cristóvão, SE, Brasil, e-mail: rosanagivigi@uol.com.br

Recebido em Dez. 9, 2011; $1^{\text {a }}$ Revisão em Mar. 7, 2012; $2^{\text {a }}$ Revisão em Maio 15, 2013; $3^{\text {a }}$ Revisão em Set. 3, 2014 ; Aceito em Dez. 15, 2014. 


\section{Introdução}

Ao percorrermos a história de famílias que recebem o diagnóstico de patologia de seus filhos o que vemos é a destituição dos sonhos, discursos de culpa, de desistência, de lamento, de ilusão (CAMARGO; ZAMPIERI, 2005; ARIÈS; DUBY, 2009a e 2009b). Coexistem sofrimento e esperança. Pensar essa mistura pode convocar um exercício de criação de dispositivos que extrapolem a clínica tradicional, que criem uma prática que se dê na experimentação, o que não significa um descompromisso com a teoria e com a ética, pelo contrário, exige rigor.

Para ampliar a maneira de se ver a clínica, posturas, concepções e crenças devem ser colocadas em suspensão, reconhecendo-se que "fazer com" significa romper com o instituído, bagunçar as peças e reorganizá-las.

Precisamos, ao mesmo tempo, de prudência e de ousadia para evitar os riscos de se grudar na ignorância dos valores morais, classificatórios, excludentes e mortificantes. Pois, quando não se "compreende", moraliza-se e destila-se o imperativo de um "dever" constituído pela "vontade de verdade", ou seja, o desejo de dominar, subjugar, humilhar, desqualificar o outro, como se fôssemos donos de uma verdade absoluta sobre tudo e todos (MACHADO; LAVRADOR, 2009, p. 520).

Esse é o movimento que será apresentado neste trabalho; uma clínica que para a Fonoaudiologia se configura no início da década de 1990, com a clínica da subjetividade, que advém do diálogo com disciplinas e teorias que se distanciam do modelo positivista. Destacam-se nesse diálogo a Análise do Discurso de linha francesa, o Interacionismo Brasileiro, a Psicanálise e a Teoria da Enunciação (BALESTRO; RAMOS-SOUZA, 2008). Aqui a clínica se desprenderá do setting fonoaudiológico como espaço único e se amarrará às redes família e escola.

Portanto, essa proposta de clínica diverge das ideias da clínica tradicional, onde o paciente é visto apenas no espaço terapêutico, sem levar em conta suas redes de relação. Deseja pensar além do trabalho fonoaudiológico, propõe-se pensar o fazer clínico na área da saúde, vinculando o paciente às redes nas quais está inserido.

Dessa forma, este estudo partiu da Análise do Discurso de pais sobre as alteraçóes de linguagem de seus filhos e seu objetivo foi analisar os efeitos do trabalho de intervenção com crianças, suas famílias e escolas. A intervenção teve como meta a construção da linguagem e a modificação dos sentidos atribuídos a esses sujeitos. Pautou-se no desejo de promover rupturas com as concepçóes cristalizadas, modificando o sentido dado às alteraçôes de linguagem e as açôes resultantes desses sentidos.

\section{$2 \mathrm{O}$ trabalho em redes}

Todas as pessoas frequentam diferentes espaços, conhecem diferentes pessoas, têm diferentes relações e essas serão aqui referidas como rede. A noção de rede está presente em todas as áreas, é polissêmica. A sua origem vem do latim retiolus diminutivo de retis, que significa rede de caça ou pesca e tecidos, fios entrelaçados.

As redes serão pensadas como símbolos, constituídas por uma pluralidade de ligaçóes e de caminhos; interconexóes instáveis, pois se modificam sistematicamente, e dinâmicas, por estarem em constante movimento. As redes são os vínculos que se apresentam muitas vezes invisíveis, mas sempre de lugares visíveis. Vínculos que são variados, instáveis e misturados a outros vínculos (BARBOSA, 2004).

Relacionada à noção de rede apresentada anteriormente e ampliando a ideia para o campo da Semiótica construiu-se o conceito Rede de Significaçóes, que reconhece as interaçóes dos diferentes níveis (macro e micro), mas a dimensão semiótica assume caráter central. A noção de significado é a sustentação da rede (YAZLLE; AMORIM; ROSSETTI-FERREIRA, 2004; ZANELLA, 2003).

O que se vê no outro é visto a partir de uma Rede de Significações; significações construídas a partir dos fatores sócio-históricos, de processos particulares de significação, de processos psíquicos, que produzem e são produzidos pela cultura, que modificam e são modificados pela cultura (ROSSETTI-FERREIRA et al., 2003).

Nessa perspectiva torna-se impossível pensar o indivíduo e suas açóes dissociados desse campo interacional e de seu contexto, numa relação dialética entre fatores políticos, históricos, sociais, econômicos e culturais, entendendo que não existem relaçóes homogêneas. Rompe-se com a ideia de uma natureza para o indivíduo, apontando para uma visão prospectiva da vida, uma visão de desenvolvimento sem linearidade.

Como dizem Rossetti-Ferreira et al. (2004, p. 31): 
[...] a Rede de Significações não existe como uma entidade, mas é uma apreensão pelo pesquisador da situação investigada e uma interpretação de como os componentes apreendidos articulam-se e circunscrevem certas possibilidades de ação, emoção, cogniçáo.

\section{A linguagem e a formação dos sentidos}

Segundo os princípios do Interacionismo, a compreensão do indivíduo depende da relação dialética entre o indivíduo e seu contexto sóciohistoricocultural, por se acreditar que o homem e seu meio estâo implicados numa rede na qual um age sobre o outro, num processo de recorrentes transformações (VYGOTSKY, 1998).

O Interacionismo Vygotskyano pensa a linguagem como uma função mental superior e a circunscreve como a instância máxima da subjetividade do sujeito. Assim, Vygotsky (1996, 1989 a, b) concebe o homem como um ser sociocultural, afirmando que seu desenvolvimento se dá inicialmente no plano intersubjetivo e depois no plano intrassubjetivo. No desenvolvimento assim concebido, vige a concepçáo de que o sujeito não significa o mundo para, a partir de então, representá-lo pela linguagem, mas sim que essa significação se constrói também pela própria linguagem, ou, ainda, a linguagem terá um papel fundamental como mediadora das interaçóes e da significação do mundo.

A linguagem neste trabalho será vista como sendo não transparente, pois tanto as palavras quanto enunciados náo possuem sentidos cristalizados, fixos, únicos, sentidos esses que diversificam-se a cada olhar lançado sobre eles. A linguagem possui caráter polissêmico, é de natureza múltipla, visto que varia de acordo com o contexto em que está inserida.

A linguagem é entendida como funcionamento simbólico e que, como tal, não é transparente, não se dá a ver em sua completude, até porque a incompletude é um traço que lhe é inerente. Trata-se de adotar uma concepção que toma a linguagem como discurso, efeito de sentidos, o que nos permite pensar que cada produção linguística é singular, fruto da confluência de múltiplos sentidos (SALFATIS; PALLADINO, 2001, p. 32).
Assume-se aqui o conceito de linguagem como produtora de sentidos, que leva em consideração tanto a intersubjetividade como a interdiscursividade inerentes às relaçóes constitutivas dos sujeitos. A noção de sujeito traz à tona uma alienação à linguagem mediante a interação.

A linguagem possui uma relação com o corpo muito próxima, ou melhor, inseparável. Muitas formas de dizer encontram no corpo um suporte que algumas vezes náo se acha nas palavras. Segundo François, "o sentido não está em um enunciado, mas no conjunto das trocas linguísticas e no modo como ela modifica a situação" (FRANÇOIS, 2006, p. 189).

Seguindo essas ideias, os olhares se desviam da patologia para as relaçóes que constituem a linguagem. Nesse sentido, tomando as relaçôes como unidades de análise do processo de construção da linguagem, os estudos de Cláudia De Lemos deram suporte ao estudo dos processos dialógicos. Seus estudos trazem os três processos dialógicos: a especularidade, a complementaridade e a reciprocidade (DE LEMOS, 1989, 2006).

Segundo De Lemos (1989), o primeiro inicia-se pelo movimento do adulto, esse espelha as vocalizaçóes da criança, ao fazer isso também atribui significado e intencionalidade ao que a criança diz. A seguir, o processo se reverte e o movimento passa a ser da criança, que espelha o que é reproduzido pelo adulto.

No processo de complementaridade, o que acontece é a retomada do enunciado do outro, isso é feito no sentido de complementar ou expandir os fragmentos de fala. Num primeiro momento é feito pelo adulto, depois pela criança.

Quando a criança assume os papéis dialógicos que antes eram do adulto, será vista a construção do processo de reciprocidade ou reversibilidade.

Como foi dito anteriormente, a linguagem submete-se a dois processos, em especial: ao das relaçóes intersubjetivas e aos processos de construção do sujeito. Como destacaria Orlandi (2002), o discurso, constituído pela linguagem, é tratado na possibilidade múltipla de significar, nos diversos sentidos que assume, de acordo com as situaçôes vividas pelo sujeito na sua realidade. Enfim, baseados na Análise do Discurso, acredita-se que sujeito e sentido constituem-se simultaneamente.

De acordo com essa perspectiva, a meta inicial baseia-se na compreensão de como os objetos simbólicos produzem sentidos. Somente a partir dessa compreensão será possível lançar um novo 
olhar para o mesmo objeto. Toda análise envolve processos singulares que no movimento de análise e de interpretação podem ganhar um novo sentido, observando assim resultados diferentes sobre aquele mesmo objeto (ORLANDI, 2003).

Os sentidos têm relação com o que foi dito em determinado instante ou até em outros momentos, assim também com o que não foi dito e com o que poderia ser dito e não foi. Sendo assim, pode-se dizer que:

A Análise do Discurso não procura o sentido "verdadeiro", mas o real do sentido em sua materialidade linguística e histórica. A ideologia não se aprende, o inconsciente náo se controla como saber. [...] lugar do outro enunciado é o lugar da interpretação, manifestação do inconsciente e da ideologia na produção dos sentidos e na constituiçấo dos sujeitos (ORLANDI, 2003, p. 59).

Dito isso, os sentidos e os sujeitos constituem-se por meio de processos onde há transferências, jogos simbólicos dos quais não se tem o controle.

Norteando-se por essa perspectiva, acredita-se que a interação não se dá apenas no âmbito terapêutico; ela não está dissociada das outras redes nas quais a criança está imersa, a exemplo da escola e família. Assim, o trabalho deseja de promover rupturas nas concepçốes cristalizadas, modificando o sentido dado às alteraçóes de linguagem e às açóes resultantes desses sentidos.

\section{Metodologia}

Esse estudo foi realizado na Universidade Federal de Sergipe e aprovado pelo Comitê de Ética em pesquisa da Universidade conforme parecer $n$. CAAE-0133.0.107.000-08. Todos os responsáveis pelos sujeitos envolvidos neste trabalho consentiram na realização desta pesquisa e na divulgaçáo de seus resultados.

A pesquisa foi de caráter qualitativo. Utilizou-se a Metodologia Clínico-Qualitativa, que é definida a partir de métodos científicos, técnicas e procedimentos que buscam descrever e interpretar os fenômenos analisando os sentidos atribuídos à vida dos pacientes ou de qualquer outra pessoa participante do setting terapêutico (TURATO, 2003).

Além da Metodologia Clínico-Qualitativa, o trabalho também fundamentou-se na pesquisa-ação colaborativa. Rejeitando-se as noçôes positivas de racionalidade, de objetividade e de verdade, num trabalho de colaboração, a disposição foi pensar as contradiçóes e os confrontos. Metodologicamente, na pesquisa-ação colaborativa,

o pesquisador é um participante engajado. Ele aprende durante a pesquisa. Ele milita em vez de procurar uma atitude de indiferença (BARBIER, 2004, p. 62).

\section{O processo de seleção}

Para contar a trajetória desse grupo iniciamos com a seleção das famílias que participariam do trabalho. Como era preciso definir os sujeitos, os critérios de elegibilidade utilizados foram estar na faixa etária de zero a cinco anos e ter alteração de linguagem apresentada em sua descrição diagnóstica.

As crianças foram localizadas a partir de uma lista do Centro de Referência em Educação Especial do Estado de Sergipe, que já continha dados como nome, idade e diagnóstico. O contato foi feito por ligação telefônica, com explicação sobre o projeto e um convite para participar dele. A partir de uma afirmativa interessada, agendou-se um horário possível para a realização da segunda etapa: a entrevista inicial e a visita domiciliar. Logo depois foram feitos cinco encontros com a criança e, por fim, a devolutiva para os pais a respeito das impressōes e interpretaçóes em um Relatório Fonoaudiológico entregue a eles após o diálogo. Esse processo foi avaliativo e antecedeu os atendimentos, não fazendo parte do quantitativo de atendimentos apresentado abaixo.

\section{Os sujeitos da pesquisa}

Guido $^{2}$ foi a primeira criança a integrar nosso grupo. Tinha quatro anos e o diagnóstico de Distúrbio do Espectro Autístico. Esse diagnóstico foi dado quando tinha três anos. Ele não tinha irmãos, mas sua mãe estava grávida de uma menina. Morava com os pais no povoado de Sobrado, que tem uma população pequena e está localizado no município de Nossa Senhora do Socorro, na região metropolitana de Aracaju, SE. Estava na escola regular.

A segunda criança a integrar o grupo foi Vivian. Ela tinha dois anos de idade e seu diagnóstico era Paralisia Cerebral mista quadriplégica severa. $\mathrm{O}$ diagnóstico foi dado pelo neurologista quando Vivian tinha dois meses. Vivian reside com os pais e com os irmáos em uma casa localizada num bairro 
pobre, periférico e considerado o mais violento da cidade de Aracaju. Não estudava.

A próxima criança foi Wilma, de 4 anos, com diagnóstico de Distúrbio do Espectro Autístico e Epilepsia. O diagnóstico foi dado quando ela tinha três anos e meio pelo neurologista. Seus pais eram separados e Wilma tinha pouco contato com a figura paterna, que apenas fornecia ajuda financeira. Wilma morava com a mãe na zona norte de Aracaju. Estudava em uma escola para crianças especiais.

Carlos, um menino de quatro anos com atraso na linguagem, chegou sem diagnóstico concluído. É o filho mais velho do segundo casamento do pai. Morava em uma casa pequena, no centro da cidade de Aracaju, com os pais, a irmã e a avó paterna. Não estudava.

Marcos, a última criança apresentada, tinha três anos. Seu diagnóstico era de Distúrbio do Espectro Autístico, dado pelo neurologista quando ele tinha três anos. Marcos morava com a mãe em um bairro periférico da cidade de Aracaju. Tinha contato esporádico com a avó paterna e o pai. Estudava em escola regular.

\section{Procedimentos}

Após a seleção iniciou-se o trabalho com a criança, a família e a escola. Entretanto, este artigo será um recorte de um projeto do grupo de pesquisa A Construção da Linguagem, Patologias e a Prática Clínica, que tem como objetivo refletir sobre o funcionamento da linguagem visando à compreensão de sua dimensão patológica, portanto numa abordagem mais ampla e dando oportunidade para muitas questôes de pesquisa.

O processo de intervenção que fez parte desta pesquisa perdurou de junho de 2008 até junho de 2010 e objetivou analisar os efeitos do trabalho de intervenção com as crianças, sua família e sua escola. A intervenção teve como meta a construçáo da linguagem e a modificação dos sentidos atribuídos a esses sujeitos.

Os sujeitos selecionados foram atendidos em terapia fonoaudiológica semanalmente, inicialmente visando o processo interacional como disparador da construção da linguagem. A terapia acontecia na universidade, numa sala de atendimento de casos de alteração na linguagem. Essa sala é equipada com brinquedos, jogos, materiais audiovisuais, computadores, materiais específicos da linguagem e mobiliário infantil.

Durante o período da pesquisa foram no total 25 atendimentos em terapia com Guido, 20 atendimentos com Vivian, 16 atendimentos com Wilma, 12 atendimentos com Carlos e 22 atendimentos com Marcos. A variação dos números se deve à data em que cada um entrou no grupo e à assiduidade.

Com as famílias, os procedimentos envolveram entrevistas individuais, visitas domiciliares e grupo de pais. As entrevistas individuais aconteceram na mesma sala em que acontecia a terapia, só que em outros horários. Elas eram estratégicas para tratar das questóes que surgiam nos atendimentos terapêuticos com as crianças, nesses momentos eram resgatadas situaçôes da terapia e, também, situaçóes trazidas pela família. Já as visitas domiciliares tinham como objetivo conhecer as realidades vividas, valorizando os aspectos socioculturais e suas influências no desenvolvimento infantil.

No grupo de pais, que acontecia quinzenalmente numa sala de reunióes da universidade, eram debatidos diferentes assuntos que levavam em conta as angústias, os medos, as experiências e anseios de cada um desses familiares, bem como temas relacionados à Fonoaudiologia, como: a linguagem, diferentes formas de comunicação, a interação, a brincadeira simbólica, dentre outros. O foco era a troca de conhecimento no grupo, na tentativa de promover rupturas com o que estava naturalizado como, por exemplo, a concepção de que por não falarem não deveriam estar na escola regular, ou que o fato de não falar significava também não pensar, ou alteração no funcionamento cognitivo. A Tabela 1 mostra o número de entrevistas individuais realizadas, a presença no grupo de pais e o número de visitas domiciliares. A variaçáo dos números se deve à data de entrada de cada um no grupo e à assiduidade.

Tabela 1. Demonstrativo das ações desenvolvidas junto às famílias.

\begin{tabular}{cccc}
\hline & ENTREVISTAS & GRUPO DE PAIS & VISITAS DOMICILIARES \\
\hline Guido & 7 & 10 & 5 \\
Vivian & 7 & 19 & 4 \\
Wilma & 8 & 11 & 4 \\
Carlos & 6 & 8 & 5 \\
Marcos & 10 & 9 & 4 \\
\hline
\end{tabular}


Nas escolas, o acompanhamento era semanal. Inicialmente foi feita uma observação do espaço físico bem como da dinâmica escolar, além de uma interação com a equipe pedagógica, visando conhecer de que forma o trabalho com essas crianças estava sendo realizado. Foram levadas em consideração as dificuldades e necessidades das crianças, na tentativa de propor um trabalho em conjunto direcionado a cada realidade. Como no início do trabalho não tínhamos todas as crianças na escola, os números de visitas aparecerão apenas na discussão.

A cada passo da coleta de dados foram feitas análises, categorizadas segundo regularidades. Essas regularidades foram constituídas pela frequência que apareciam no próprio corpus. As análises seguiram os princípios do Interacionismo e da Análise do Discurso, usando as ferramentas metodológicas da pesquisa-ação e da Rede de Significações (TURATO, 2003; JESUS, 2008; ROSSETTI-FERREIRA, 2003).

\section{Resultados e discussão}

O trabalho foi pensado no tripé criança-famíliaescola. A discussão dos resultados se dará sobre como o trabalho com as redes pode promover a construção da linguagem e modificar os sentidos das alteraçôes de linguagem e, consequentemente, as açóes cotidianas das pessoas que convivem com esses sujeitos.

\section{Refletindo os efeitos do trabalho na família}

Divergindo da concepção objetiva da família e das práticas fonoaudiológicas que partem do pressuposto de que essa instituição é responsável pelos distúrbios da comunicação e que a família deve atuar como coterapeuta no processo, a visão subjetiva, assumida pelo grupo, lança um novo olhar sobre a linguagem e o sujeito, bem como sobre a família. Esse olhar tem como sustentação as ferramentas teóricas do Interacionismo.

$\mathrm{Na}$ sociedade, alguns discursos se legitimam e se naturalizam sustentados em regimes de verdade que querem delimitar as regras da dinâmica social. Dentre as formas de dominação, os discursos que naturalizam sentidos são fortes aliados.

Os processos de naturalização são aqui entendidos como mecanismos que agem pela via da des-historicização da ordem social e dos discursos que a sustentam (NARDI, 2006, p. 166).

Em relação às patologias isso não é diferente, muitos discursos são naturalizados, por exemplo, que a alteração de linguagem está sempre relacionada a deficiências intelectuais e que esses sujeitos náo terão vida produtiva. Partindo do princípio de que os indivíduos podem se reorganizar e construir outras formas de relacionarem-se com esse regime de verdade, novas práticas podem ser inventadas, novos esquemas propostos. Os estudos apontam para a necessidade de desnaturalização da patologia, o rompimento com e de suas consequências (GIVIGI, 2007; BARBOSA, 2004; NARDI, 2006). Diversos trabalhos vêm discutindo a importância das representaçôes e sentidos dados às alteraçôes de linguagem (LEMOS; BARROS; AMORIM, 2006; SERAPOMPA; MAIA, 2006; ROSA; ROSSIGALLI; SOARES, 2010; RESENDE; FERREIRA; ROSA, 2010).

Nos primeiros encontros verificou-se que os sentidos dados aos filhos estavam vinculados a incapacidade, a dependência, a patologia. Algumas falas dizem desses sentidos:

"Marcos... assim ele tem três anos e seis meses e não fala nada... assim... nem mamãe... eu sentia que ele não era normal... eu olhava as outras crianças... percebia o jeito dele, né... meio parado. Eu protejo ele demais... tudo assim... é comigo... ele não sabe se virar só" (mãe de Marcos, entrevista inicial). "Eu acho que ela chora assim por causa da paralisia cerebral, né" (mãe de Vivian, segunda entrevista).

Esses sentidos resvalavam nas relaçóes, tratavam seus filhos como bebês, não permitiam conflitos, satisfaziam todas as necessidades rapidamente e não permitiam que muitos se aproximassem deles.

"Ele é bem dependente... eu me sinto bem, né? Porque eu não quero dividir ele com ninguém" (mãe de Marcos, terceira entrevista). "Eu não tenho confiança de deixar ela com ninguém, não conseguem cuidar direito, ela não fala" (mãe de Wilma, segunda entrevista).

Juntamente com isso, não frequentavam lugares habituais a que as crianças costumam ir ou não brincavam com elas. $\mathrm{O}$ cuidado tomava o espaço da relação. $O$ fato de não falar aparecia como uma marca para o estranho, o diferente, impeditivo das relações sociais.

"Eunão brinco comela não, ela nãosabe brincar, ela nem fala” (mãe de Wilma, segunda entrevista). 
"Ele é criado muito sozinho... eu moro só com ele... ai não saio... eu vivo presa. No parquinho eu tenho sempre problema com ele, as pessoas olham, acham ele estranho, ele não fala, né? (mãe de Marcos, terceira entrevista).

A ideia era construir uma visão mais prospectiva sobre a criança, proporcionando um ambiente que suscitasse a constituição desse sujeito na linguagem. Isso foi feito ao longo do trabalho através das entrevistas individuais e nos encontros do grupo de pais.

O grupo, ao longo da sua trajetória, deparou-se com alguns percalços como, por exemplo: a ausência de alguns pais e/ou idas esporádicas de alguns deles aos encontros; as dificuldades de eles constituírem-se como interlocutores; problemas relacionados à interação e à organização da família, para que possibilitassem uma maior autonomia das crianças; alguns apresentaram dificuldade no reconhecimento de que precisavam substituir a comunicação verbal por outros recursos comunicativos; a resistência de alguns pais em colocar suas crianças na escola regular.

Porém, através da fluidez do discurso, as discussóes e debates travados nesses momentos se articularam para o processo de mudança de olhar. Os discursos foram ganhando outra forma, outros sentidos. Pode-se apontar algumas mudanças, efeitos produzidos pelo trabalho grupal e individual, como: utilização de outras formas de comunicação; crianças frequentando e participando de mais espaços sociais; maior entendimento do que constitui a linguagem; construção de confiança no grupo de pais; sentimento de parceria e colaboração; as falas dos pais sobre as possibilidades das crianças; transformaçóes no discurso dos pais envolvidos quanto aos sentidos dados à escola regular, bem como o reconhecimento da importância desse processo para o desenvolvimento da criança. As falas a seguir mostram essas mudanças no discurso:

"Ela mudou bastante em termos de conversar. Quando eu cheguei aqui, ela era mais calada, mais muda. Ela tá se expressando sozinha. Ela tá parando mais com a coisa de ficar repetindo, entendeu? (mãe de Wilma, $11^{\circ}$ encontro do grupo de pais). "Ele está muito independente, muito independente mesmo" (mãe de Guido, $10^{\circ}$ encontro do grupo de pais). "A escola foi ótima para ele, aprendeu a brincar e tem um monte de amigos. Eu tinha muito medo, mas deu certo" (mãe de Carlos, sétima entrevista).
A mudança na forma de olhar as dificuldades de seus filhos foi propulsora para que modificassem atitudes, como corrigi-los, brincar com eles, levá-los ao shopping. A interação entre pais e filhos estava se modificando, algumas mães relatavam que os pais agora não tinham medo de sair com seus filhos $\mathrm{e}$ levá-los a lugares a que antes não iam, como para jogar futebol. Afirmamos que os sentidos não se modificaram apenas pelo diálogo, mas porque os pais viram as mudanças no comportamento de seus filhos. É uma mudança em espiral: novas açôes produzem novos sentidos e os discursos produzem a prática e, ao mesmo tempo, são produzidos com ela (GIVIGI, 2007).

\section{Refletindo os efeitos do trabalho na escola}

No início do trabalho, das cinco crianças atendidas, três estavam na escola e, dentre essas, duas em escola regular e uma em escola especial. Nosso trabalho inicial foi de conhecer as escolas. As três crianças que estavam em escola tinham os pais insatisfeitos com o trabalho. A que estudava em escola especial, a partir da intervençáo, passou a estudar em escola regular, e as duas restantes continuaram em sua escola. As outras duas crianças entraram em escola regular somente em 2009.

Ao conhecer a escola especial em que uma das crianças estudava observou-se uma conduta mais clínica do que educacional. Faziam sessōes de Fisioterapia e Fonoaudiologia e ficavam na sala de aula com atividades chamadas de "estimulação". Durante nossa estada na escola, o que mais acontecia era as crianças brincarem livremente ou dispersas pelo espaço.

As outras duas crianças que estavam no ensino regular frequentavam escolas de bairro, sendo elas privadas mas de pequeno porte (100 alunos), com sérios problemas de infraestrutura, bem como no trabalho pedagógico.

No ano de 2009, a configuração se modificou. Todas as cinco crianças que participavam da pesquisa estavam em escola de ensino regular, instituiçóes localizadas na capital, Aracaju, e em um município que integra a regiáo metropolitana, que é a cidade de Nossa Senhora do Socorro. Uma era pública e quatro eram privadas, todas em bairros de periferia.

Ao todo foram 30 encontros na escola de Guido, 28 encontros na escola de Vivian, 32 encontros na escola de Wilma, seis encontros na escola de Carlos e 20 encontros na escola de Marcos. A variação de 
número se justifica pela época que cada criança entrou na escola, pela assiduidade e pelos acordos feitos em cada escola com gestores e professores.

O fato de essas cinco crianças estarem na escola (todas em ensino regular) já diz muito do trabalho. Num primeiro momento, os pais não cogitavam a ideia de matricular os filhos numa escola regular, apesar da insatisfação decorrente de estarem em escola especial ou de náo estarem na escola. No grupo de pais, essas questôes foram fomentadas e houve a abertura para possibilidade de se pensar em outros processos escolares. As duas crianças que já estavam no ensino regular continuaram na mesma escola.

Para que pudesse ser feita a escolha da escola para as crianças primeiramente foi feito o reconhecimento de todas as escolas do bairro em que cada criança residia. Foram, ao todo, cinco bairros e nove escolas visitadas, na sua maioria escolas públicas. Das nove escolas visitadas apenas duas mostraram-se receptivas e interessadas em conhecer a criança e a família. A grande maioria dizia da impossibilidade de receber uma criança deficiente e, quando questionadas, não tinham conhecimento da Lei de Diretrizes e Base (LDB) de 1996. Acompanhamos as famílias numa visita às escolas selecionadas e, depois disso, cada família decidiu por uma escola e as matrículas foram feitas.

As dificuldades estavam apenas começando. Tínhamos, então, no início de 2009, cinco escolas para trabalhar. De todos os professores, $50 \%$ tinham curso superior, mas o restante possuía apenas o nível médio. Em duas das escolas privadas a remuneração era meio salário mínimo, o que tornava difícil motivar esses docentes a buscar formação continuada, que deveria ser realidade em todos os lugares. A formação continuada possibilita ao professor entrar em contato com outras formas de saber e, dessa forma, encontrar nos espaços heterogêneos as possibilidades de inclusão e construção de sujeitos críticos (JESUS, 2008; ZANELLA, 2003).

As escolas públicas tinham pedagogos e coordenadores; somente em uma das escolas privadas havia pedagogo e, nas outras, o dono era alguém da comunidade. Quanto à infraestrutura, percebeu-se que era mais adequada nas escolas públicas, que possuíam, na sua maioria, espaços externos para lazer, além de pequenas bibliotecas e salas de tamanho adequado para o número de alunos. Já nas três escolas privadas apenas uma delas tinha estrutura adequada; as outras duas eram na casa da própria dona, sem as adaptaçóes adequadas para que funcionassem como escola.
Num primeiro momento, em todas as escolas trabalhadas percebeu-se certo alívio, pois as professoras relataram que não sabiam o que fazer, nunca haviam ensinado crianças com deficiência e sabiam um pouco o que era a patologia.

No plano do discurso, todos participaram ativamente. $\mathrm{O}$ funcionamento do discurso se dá na tensão entre o mesmo e o diferente, ou, respectivamente, entre os processos parafrásticos $\mathrm{e}$ os processos polissêmicos. Os sujeitos e os sentidos são movimentados por esse jogo e, assim, se significam e se refazem.

Os processos parafrásticos são aqueles pelos quais em todo dizer há sempre algo que se mantém, isto é, o dizível, a memória. A paráfrase representa assim o retorno aos mesmos espaços do dizer. Produzem-se diferentes formulaçóes do mesmo dizer sedimentado. A paráfrase está do lado da estabilização. Ao passo que na polissemia o que temos é deslocamento, ruptura de processos de significação. Ela joga com o equívoco (ORLANDI, 2003, p. 36).

Quando se diz isso, afirma-se que não há discurso sem repetição, mas também há a multiplicidade de movimentos de sentido. Nos episódios a seguir os discursos aparecem com movimentos parafrásticos e polissêmicos:
"Não sei se esses alunos deviam estar na escola, eles não aprendem fácil, não têm estrutura..." (professora A., terceiro encontro). "Eles colocam as crianças aqui e não dão estrutura, era melhor estarem na escola especial" (professora A., depois de oito encontros). "Não sei... falta tudo, eles têm dificuldade, mas é importante estarem aqui, aprenderem coisas novas, mesmo com a deficiência eles conseguem" (professora A., depois de 18 encontros).

$\mathrm{Na}$ escola temos um espaço rico em interação. Esses processos interacionais são imprescindíveis para a aprendizagem; é na relação com o outro/ mediador que se transforma a atividade mental. A qualidade e intensidade da interaçáo podem agir sobre as relaçóes de maneira ampla, reverberando na aprendizagem formal, nas atitudes diárias, na vida social.

Pensar o trabalho de colaboração significa estar disposto a um exercício de autonomia do pesquisador e dos sujeitos pesquisados, no caso, os professores. O que se propóe é um trabalho de formação docente no dia a dia da escola e com o professor ativo no processo. Tem-se chamado isso de "empoderamento, isso é, um processo de construção 
do poder dos sujeitos que dele participam; poder aqui entendido como consciência de si como sujeito da práxis" (FRANCO; LISITA, 2008, p. 49).

O trabalho aconteceu semanalmente, com a proposta de diálogo e interlocução para a produçáo de práticas reflexivas e conhecimento. Como diz Franco e Lisita (2008), esse diálogo visto criticamente poderia levar a superar o senso comum, mesmo que ele fosse ponto de partida.

Como eram cinco escolas, não se pode falar de uma única forma de fazer, mas neste texto serão feitos agrupamentos e esses têm como meta mostrar as regularidades dos trabalhos. Entenda, caro leitor, que houveram diferentes propostas nas escolas; elas não eram homogêneas e nem seguiam a mesma ordem, nem o mesmo tempo. Os processos foram instituindo-se de diferentes formas.

No início, a opção foi interferir pouco e participar quando convidado. Mais isso não durou muito e, dessa forma, numa média de dois meses fomos instigados a ocupar outros lugares. Então a ideia foi fazer propostas diretas de trabalho, nesse momento nada colaborativo, porque muitas vezes era feito por nós. Envolver os professores não foi fácil; em algumas escolas houve atrito, noutras, acolhida, mas a diversidade foi enfrentada nos processos de construção.

Uma estratégia foi participar dos momentos de recreio. Junto com as crianças eram feitas propostas que incluíam a todos nas brincadeiras e observa-se que as relaçôes já começavam a ser modificadas. As brincadeiras incluíam as crianças com deficiência, mas isso só acontecia a partir de nossa mediação.

O recreio é importante porque as relações sociais são fundantes do sujeito, sendo continuamente a arena e o motor da constituição do mesmo. É por meio do funcionamento dos processos dialógicos que se constroem as "interaçôes", em que cada sujeito tem seu fluxo de comportamento delimitado, recortado e em constante interpretação pelo outro e por si próprio. Assim, na ação dialógica o sujeito interage, transforma e é transformado por seu parceiro. Concomitantemente, modificam-se as funçôes psicológicas que os regem, remodelam-se seus propósitos e abrem-se novas formas de ação, interação e construção (RAHME; MRECH, 2009).

As salas de aula traziam diversos desafios. Muitas vezes as práticas pedagógicas eram distantes do que entendíamos como producente, além do que faltava disposição, didática, atividades e materiais. Outros trabalhos falam dessa distância, como os de Rossetti-Ferreira et al. (2003) e de Givigi (2007).
Depois de conhecer a escola e seu plano pedagógico, além da estratégia do recreio, executou-se a proposta de fazer em conjunto um planejamento pedagógico para as turmas que deveriam incluir o trabalho com multiníveis. Assim, diversos planos foram construídos e atividades, preparadas. Em três escolas houve a adesão dos professores, mas em duas delas trabalhamos quase sozinhas, num primeiro momento. A partir de mais essa estratégia, o movimento de fazer junto suscitou nos professores uma energia que antes não era percebida.

Outro trabalho desenvolvido nas escolas foi o trabalho de formação continuada com professores. Em duas escolas todos os professores foram reunidos para discutirem-se questóes variadas, entre elas a inclusão, o trabalho multiníveis e formas de linguagem. Nesses encontros surgiram muitas dúvidas e inquietações e respondemos às questóes falando da prática.

Nesses momentos junto com os professores eram trazidas questóes cotidianas, algumas antigas e outras novas. Era recorrente a discussão sobre a diversificação dos momentos e das estratégias de ensino na mesma sala de aula. Esses fatores eram levantados como elementos importantes para que a inclusão fosse eficaz e "o aprender" fosse para todos.

Apesar de muitas mudanças serem percebidas nas escolas, em duas, especialmente, o trabalho desenvolvido ainda ocorria com problemas que acarretavam morosidade ao processo. Buscaram-se açôes junto à docente, mesmo que de maneira lenta, além de pesquisarem-se outras açóes efetivas na escola. Interferíamos nas atividades, ajudávamos no controle da turma, participávamos dos recreios.

As questôes referentes à linguagem se fizeram presentes desde nossa entrada nas escolas. Das cinco crianças, nenhuma falava, mas todas tinham outras formas de se comunicar. Comparecia, de maneira recorrente, a ideia de um sujeito com pensamentos preconcebidos por conta da patologia instalada em seu corpo. As limitaçóes do corpo se sobrepuseram à dinâmica da linguagem por conta dos discursos cristalizados e, em decorrência disso, os sinais discursivos dos nossos sujeitos iam sendo escondidos pela fala da impressão, a marca de deficiente. A aprendizagem, que deveria ser o foco desse ambiente institucional, perdeu sentido a partir do momento que esses sujeitos foram tomados como desprovidos de linguagem. Dessa maneira, o contato era iniciado, mas quase nunca estendido. Se a linguagem se constrói nessa interlocução, na atribuição de sentidos dos interlocutores, encontramos um vácuo nessa construção, nessa 
relação que vinha se estabelecendo na escola ou, se preferirmos, nessa falta de relação.

A simplificação da linguagem dificultava as intervençôes. O sentido de que linguagem não é fala e de que existem outros meios de linguagem parecia náo ser compreendido pelos que vivenciavam a docência. A determinação de um sintoma na criança ocultava o que nos parecia ser mais problemático: o despreparo em lidar com o diferente, com a singularidade que cada sujeito manifesta. As simplificaçóes deixavam escorrer um emaranhado de sentidos que a todo momento eram expressos pelas crianças, algumas vezes pelo movimento corporal ou pelo choro, noutros momentos pela recusa em olhar.

Vygotsky (1989a) fala do sujeito da e para a linguagem, essa entendida como um universo complexo diretamente ligado ao pensamento, como uma relaçáo cíclica, trata-se de um processo dialético. Para o autor, o desenvolvimento, apesar de envolver processos biológicos, é especialmente cultural, histórico e social.

Dessa forma, os processos psíquicos superiores são históricos e, portanto, resultado da construção histórica da humanidade. As ideologias, nesse sentido, não são constituição própria do sujeito, mas constituídas pelo intersubjetivo.

O trabalho foi marcado por dificuldades e algumas constituíram-se como recorrentes: os sentidos atribuídos ao que é ter uma deficiência; a dificuldade de matricular as crianças no ensino regular; problemas relacionados à formação dos professores; as dificuldades dos professores em se constituírem como interlocutores; o processo de inclusão; a infraestrutura das escolas; a organização das escolas para acolher o projeto inclusivo; a dificuldade de interação; a dificuldade no reconhecimento de que precisariam substituir a comunicaçáo verbal por outros recursos comunicativos; a utilização de outros recursos comunicativos.

Muito além das dificuldades que se presentificavam nas escolas, o trabalho apontava para mudanças dentro da própria escola. Dentre todas as dificuldades discutidas ao longo do texto poderíamos sintetizar da seguinte forma: abertura para o trabalho colaborativo; transformaçóes nas falas dos sujeitos envolvidos quanto aos sentidos dados aos alunos, mesmo que ainda não potencializassem de forma significativa essa condição; a tentativa de se constituírem como interlocutores dos pesquisadores e das crianças; tentativas de reconhecimento de outras formas de comunicação; tentativas de envolvimento das crianças nas brincadeiras coletivas; tentativas de envolvimento das crianças nas atividades escolares; menos angústias em relação à aprendizagem e à linguagem, além de outras questôes que permeiam o cotidiano de uma criança com deficiência; a ideia de um sujeito no qual as limitaçóes do corpo se sobrepóem à dinâmica da linguagem como relacional.

\section{Refletindo sobre os efeitos do trabalho com as crianças}

O trabalho com as crianças foi de certa forma o ponto de partida, o disparador de muitas questôes. Os atendimentos utilizavam a brincadeira como estratégia. A diversidade de brincadeiras foi o elemento que facilitou muitas de nossas interpretaçôes. Foram experimentadas relações dialógicas que permeavam nossos olhares, toques $\mathrm{e}$ falas. Inegavelmente, a brincadeira é um importante recurso para o desenvolvimento humano, pois é nela que a criança experimenta diferentes papéis, confronta diferentes formas de pensar e agir. Ora é quem decide, ora é quem acata, ora transforma a regra. Brincar junto abre possibilidades para romper com sentidos cristalizados e criar outros. Sempre eram propostas novas atividades de interação. São elas que tornam possíveis o distanciamento dos sentidos e dos papéis anteriormente ocupados, assim como a construção de novas possibilidades de ação. Outros trabalhos utilizaram o mesmo referencial e obtiveram resultados semelhantes, como os de Trenche (2006) e Catrini (2008).

Os discursos que as pessoas tomam para si tornam possíveis determinadas posiçóes. Nas relaçôes com interlocutores estão em jogo essas posiçóes. $\mathrm{O}$ desejo era que a flutuação de lugares gerasse outros posicionamentos e reafirmasse as potências. A brincadeira no trabalho com esses sujeitos era a estratégia para aproximação. Com o passar dos atendimentos apareceram muitas diferenças, resultado de mudanças no funcionamento simbólico. Os episódios a seguir dão visibilidade a essa afirmação:

\footnotetext{
"Pegava os bonecos, olhava-os, mas não dava sentido à brincadeira" (quarto encontro terapêutico com Marcos). "Marcos coloca o boneco na casinha, não o joga e sim vai como se o boneco estivesse caminhando na casa, o coloca no banheiro, o boneco vai ao vaso sanitário e depois na pia.. . faz tudo silenciosamente" (nono encontro terapêutico com Marcos).
} 
A linguagem começava se presentificar de diversas formas. As brincadeiras simbólicas ganhavam espaço através de representações de situações cotidianas, de sequências de açôes, da criação de situações. O silêncio foi substituído por uma variação de sons. Muitas eram as tentativas de fala.

Outra mudança notada foi a brincadeira compartilhada. As crianças aceitavam e até convidavam o terapeuta para brincar. $\mathrm{O}$ contato pelo olhar era mais frequente, bem como outras açóes comunicativas como puxar o braço, apontar, sorrir e fazer gestos representativos.

No trabalho com as crianças constituíram-se como dificuldades recorrentes: as quebras nos atendimentos por faltas; descontinuidade do trabalho em casa; rejeição a novas possibilidades pela baixa de autoestima; uso de outros recursos comunicativos fora do espaço terapêutico.

Ao final da intervenção, mudanças também estavam presentes, como transformaçóes na maneira de os sujeitos/crianças se atribuírem sentidos e construção da linguagem, observadas no confronto nas situaçóes a seguir:

"Entrou na sala e perguntei a ele do que queria brincar, não respondeu verbalmente, mas foi diretamente para a caixinha com os animaizinhos, usada no encontro passado; de, dentro dessa caixinha pegou imediatamente o tubarão e começou falando [pesi], parou ai, náo sabia o que fazer, esperou procurando o olhar aprovador ou reprovador para continuar (segundo encontro terapêutico com Carlos). "Numa brincadeira, tirou da caixinha a Moranguinho e imediatamente disse: [moãgio nãda], querendo dizer que sua irmá Fernanda tinha, e assim como ele fez com a Moranguinho ele fez com o Rabicó, e disse que era do Sitio do Pica-pau Amarelo. Não esperava mais a aprovação, arriscava-se e muitas palavras $e$ frases emergiam $\left(10^{\circ}\right.$ encontro terapêutico com Carlos).

Outras mudanças nas atitudes e no desenvolvimento das crianças podem ser destacadas: tentativa de se constituírem como interlocutores dos pesquisadores; utilização de outras formas de comunicação; a busca na execução de novas atividades simbólicas nas brincadeiras; olhar direcionado ao interlocutor; esforço para produção verbal propriamente dita; aumento de vocabulário; aplicação de sequência de açôes nas brincadeiras; comparecimento dos processos de especularidade e de complementaridade de forma simultânea; maior compreensáo do que era dito; menos momentos de fala ecolálica; participação nas atividades dialógicas.

\section{Apontamentos finais}

As mudanças apontadas são efeitos do trabalho direto com as crianças, do trabalho no grupo de pais e do trabalho com as escolas. Conclui-se que as patologias náo devem ser ponto referencial para o trabalho que tem o linguístico como foco principal, (re)elaborando interpretaçóes a respeito de cada criança de forma singular. Importa o discurso contextualizado, dentro de suas redes e contexto histórico-social, embasando a prática em construções teóricas sólidas.

Os sentidos dados ao que era ser um sujeito com alteraçóes de linguagem configuravam a rede de certa maneira e isso interferia na forma de os sujeitos comportarem-se e nos percursos. Dependendo da situação, determinados sentidos tomavam lugar de destaque, porém no fluxo das interaçóes novas configuraçóes evidenciavam-se. Para perceber essas novas configuraçóes é preciso que o pesquisador vivencie as situaçôes, para que possa apreender os vários elementos envolvidos. Ao longo do trabalho, esses processos e suas transformaçóes foram acompanhados.

Os discursos, suas significações e sentidos foram pensados. Portanto, foi nesse entendimento que as análises tentaram extrapolar o que era dito, ver a linguagem dos gestos, das ambivalências do dizer, não deixando que houvesse uma imposição semântica para os discursos.

$\mathrm{Na}$ leitura sobre os sentidos já instituídos, não se excluem os enfrentamentos com as articulaçóes enunciativas e os indícios de sua heterogeneidade constitutiva. Somente assim é possível ver o movimento das palavras e essa foi a tentativa: ver as especificidades discursivas que constituíam certas situaçóes, mas ver/ler a partir da interpenetração com as açóes presentes na criança, na família, na escola.

Neste trabalho, foi estabelecido um lugar de tensão que permitiu que o discurso cristalizado, de negaçáo do sujeito, ganhasse novo sentido. As tensôes que ocorreram permitiram que questionamentos fossem feitos e, com isso, novos sentidos fossem produzidos.

\section{Referências}

ARIÈS, P.; DUBY, G. História da vida privada: da Europa feudal à renascença. São Paulo: Companhia de Bolso, 2009a. 
ARIÈS, P.; DUBY, G. História da vida privada: da Renascença ao Século das Luzes. São Paulo: Companhia de Bolso, 2009b.

BALESTRO, J. I.; RAMOS-SOUZA, A. P. A clínica de linguagem no autismo: terapia de dois irmãos. In: GRANA, C. G. (Org.). Quando a fala falta. São Paulo: Casa do Psicólogo, 2008. p. 143-180.

BARBIER, R. A pesquisa-ação. Brasília: Líber, 2004.

BARBOSA, M. C. S. Compromisso com a complexidade. In: ROSSETTI-FERREIRA, M. C. et al. (Org.). Redes de Significaçóes e o estudo do desenvolvimento humano. Porto Alegre: Artmed, 2004. p. 131-134.

CAMARGO, E. A. A.; ZAMPIERI, M. A. Encontros de pais de sujeitos com deficiência mental em uma clínicaescola de Fonoaudiologia. Distúrbios da Comunicação, São Paulo, v. 17, n. 2, p. 255-262, 2005.

CATRINI, M. Acontecimentos sintomaticos de fala: dispraxia verbal e sintoma na linguagem. In: CONGRESSO INTERNACIONAL DE LA ALFAL, 15., CONGRESO INTERNACIONAL DE LA ASOCIACION DE LINGUISTICA E FILOLOGIA DE AMÉRICA LATINA, 15., 2008, Montevidéo. Uruguay: Larousse; VUEF, 2008.

DE LEMOS, C. T. G. Uma abordagem sócioconstrutivista da aquisição da linguagem: um percurso e muitas questốes. In: ENCONTRO DE AQUISIÇÃO DE LINGUAGEM, 1., 1989, Porto Alegre. Anais... Porto Alegre: PUC, 1989. p. 61-76.

DE LEMOS, C. T. G. Uma crítica (radical) à noção de desenvolvimento na Aquisição de Linguagem. In: ARANTES, L.; LIER-DEVITTO, M. F. Aquisição, patologias e clínica da linguagem. São Paulo: EDUC; FAPESP, 2006. p. 21-33.

FRANCO, M. A. S.; LISITA, V. M. S. S. Pesquisaação: limites e possibilidades na formação docente. In: PIMENTA, S. G.; FRANCO, M. A. S. (Org.). Pesquisa em Educação. São Paulo: Loyola, 2008. p. 41-70.

FRANÇOIS, F. O que nos indica a "linguagem da criança”: algumas consideraçóes sobre a "linguagem". In: DEL RÉ, A. A aquisiçâo da linguagem: uma abordagem psicolingüística. São Paulo: Contexto, 2006. p. 183-200.

GIVIGI, R. C. N. Tecendo redes, pescando idéias: (re) significando a inclusão nas práticas educativas na escola. 2007. 233 f. Tese (Doutorado em Educação)-Centro Pedagógico, Universidade Federal do Espírito Santo, Espírito Santo, 2007.

JESUS, D. M. O que nos impulsiona a pensar a pesquisa-açáo colaborativo-crítica como possibilidade de instituição de práticas educacionais mais inclusivas? In: BAPTISTA, C. R.; CAIADO, K. R. M.; JESUS, D. M. (Org.). Educação Especial: diálogo e pluralidade. Porto Alegre: Mediação, 2008. p. 139-160.

LEMOS, M. E. S.; BARROS, C. G. C.; AMORIM, R. H. C. Representaçóes familiares sobre as alteraçóes no desenvolvimento da linguagem de seus filhos. Distúrbios da Comunicação, São Paulo, v. 18, n. 3, p. 323-333, 2006.
MACHADO, L. D.; LAVRADOR, M. C. C. Por uma clínica da expansão da vida. Revista Interface Comunicação Saúde Educação, Botucatu, v. 13, n. 1, p. 515-521, 2009.

NARDI, H. C. Naturalização do discurso liberal: riscos da privatizaçáo do público. In: SPINK, M. J.; SPINK, P. (Org.). Práticas cotidianas e a naturalização da desigualdade. São Paulo: Cortez, 2006. p. 189-208.

ORLANDI, E. L. P. A análise de discurso e seus entremeios. Cadernos de Estudos Lingüísticos, Campinas, n. 42, p. 21-41, 2002.

ORLANDI, E. L. P. Análise de discurso. 5. ed. São Paulo: Pontes, 2003.

RAHME, M. M. F.; MRECH, L. A convivência entre pares na escola inclusiva e seus efeitos para a constituição subjetiva: o movimento das crianças diante da diferença. In: ENCONTRO DE PESQUISA EM EDUCAÇÃO DA REGIÃO SUDESTE, 9., 2009, São Carlos. Local: Editora, 2009. p. 1-12.

RESENDE, D. O.; FERREIRA, P. M.; ROSA, S. M. A inclusão escolar de crianças e adolescentes com necessidades educacionais especiais: um olhar das Mães. Cadernos de Terapia Ocupacional da UFSCar, São Carlos, v. 18, n. 2, p. 115-127, 2010.

ROSA, S. D.; ROSSIGALLI, T. M.; SOARES, C. M. Terapia ocupacional e o contexto familiar. Cadernos de Terapia Ocupacional da UFSCar, São Carlos, v. 18, n. 1, p. 7-17, 2010.

ROSSETTI-FERREIRA, M. C. et al. (Org.). Rede de Significaçóes e o estudo do desenvolvimento humano. Porto Alegre: Artmed, 2003.

ROSSETTI-FERREIRA, M. C.; AMORIM, K. S.; SILVA, A. P. S. Rede de Significações: alguns conceitos básicos. In: ROSSETTI-FERREIRA, M. C. et al. (Org.). Redes de Significaçóes e o estudo do desenvolvimento humano. Porto Alegre: Artmed, 2004. p. 23-33.

SALFATIS, D. G.; PALLADINO, R. Interpretação: o escutar para além da palavra e do silêncio. In: PASSOS, M. C. (Org.). A clínica fonoaudiológica em questão. São Paulo: Plexus, 2001. p. 31-50.

SERAPOMPA, M. T.; MAIA, S. M. Acolhimento e inclusão: da clínica ao acompanhamento escolar de um sujeito com Síndrome de Down. Distúrbios da Comunicação, São Paulo, v. 18, n. 3, p. 313-322, 2006.

TRENCHE, M. O. Reflexóes sobre as falas ecolálicas e a interpretação fonoaudiológica a partir da discussão de dois casos de psicose infantil. Distúrbios da Comunicação, São Paulo, v. 18, n. 3, p. 335-344, 2006

TURATO, E. R. Tratado de metodologia da pesquisa clínico-qualitativa. 2. ed. Petrópolis: Vozes, 2003.

VYGOTSKY, L. S. Pensamento e linguagem. São Paulo: Martins Fontes, 1989a.

VYGOTSKI, L S. (1989) Obras Completas - Tomo V. Fundamentos de Defectologia, Ciudade de La Habana: Editorial Pueblo Educación. 
VYGOTSKY, L. S. Teoria e método em psicologia. São Paulo: Martins Fontes, 1996.

VYGOTSKY, L. S. A formação social da mente. São Paulo: Martins Fontes, 1998.

YAZLLE, C. D.; AMORIM, K. S.; ROSSETTIFERREIRA, M. C. A Rede de Significaçôes na investigação do processo de inclusão de crianças portadoras de paralisia cerebral em pré-escolas. In:
ROSSETTI-FERREIRA, M. C. et al. (Org.). Redes de Significaçóes e o estudo do desenvolvimento humano. Porto Alegre: Artmed, 2004. p. 189-206.

ZANELLA, A. V. Psicólogo na escola e as dificuldades de aprendizagem: algumas estratégias e muitas histórias. In: MARASCHIN, C.; FREITAS, L. B. L.; CARVALHO, D. C. Psicologia e educação: multiversos sentidos, olhares e experiências. Porto Alegre: UFRGS, 2003. p. 19-32.

\section{Contribuição dos Autores}

As autoras trabalharam juntas em todas as etapas de produção do texto.

\section{Notas}

${ }^{1}$ Financiamento: Fundação de Amparo à Pesquisa e à Inovação Tecnológica do Estado do Sergipe (FAPITEC) e CNPq. Aprovado pelo Comitê de Ética em Pesquisa em Seres Humanos da Universidade Federal de Sergipe conforme parecer n. CAAE- 0133.0.107.000-08.

${ }^{2}$ Os nomes das crianças são fictícios. 